Crohn's disease (not specifically illustrated 126). It is noted in the diagnostic notes at the rear of the book, but readers do not look there spontaneously as they read through the sections.

In the caption to Figure 105, there would appear to be a confusion between Tzank cells and the Tzank test, in the latter, the intercellular bridges are lost in the prickle cell layer and the cells are rounded - this is the diagnosis for Pemphigus Bullae, but Tzank cells are the cells containing virus inclusion bodies found in association with the herpes and chicken pox viruses. The same comment can be made regarding caption 109.

It is surprising that the comment on Epanutin Hyperplasia was made regarding oral hygiene in a somewhat derogatory manner - it does not occur in excellent oral hygiene cases and also there is no mention of an apparently similar condition found in patients on Sodium Valporate (Epilim), furthermore, the vascular lesions shown are not usually neoplasms and should be put in a separate category; mention could have been made of 2 other inherited conditions, gingival fibromatosis with hypertrichosis and Hunter-Hurler syndrome with its mixed bone/mucosa changes. The state of a Mongol's tongue and mouth would be better shown that cancrum oris.

However, although one may be critical of certain aspects of the book, as a whole it makes a useful reference for the undergraduate and early postgraduate; also for general practitioners. The format would be better if the more common conditions, particularly on ulcers, came first and the notes came at the end of each section instead of the end of the book where they tend to be overlooked and to break the continuity.

\section{Essentials of Radiology}

By P. M. Bretland. Pp. 178, soft cover, illustrated. Butterworths: London, 1978. $£ 8.95$.

This is a soft covered book consisting of 178 pages. It has numerous line drawings for instruction and 230 problem radiographs for the reader to interpret. The radiological subjects covered are the chest, abdomen, bones and skull. No mention is made of contrast studies, and the author concentrates on plain film interpretation. There is a list of suggested books for further reading included.

In the preface Dr Bretland says that the book is intended for the student in his first clinical year. The reviewer was quite pleased when he read this, as he has felt for a long time that there is a great need for such a book in diagnostic radiology. However, he thinks that the first year clinical student might find some of the pathological disorders beyond his grasp. It is possible, of course, that he may be stimulated to refer to other medical text books for elucidation. The content would be of greater value to the young postgraduate and indeed helpful to those intending to pursue a career in diagnostic radiology. The emphasis is on a basic scheme of approach and in this the author has succeeded. The steps to be taken in "reading" the plain X-rays of the areas covered are very clearly stated.

This reviewer can find no fault with the text, which is well written and easy to read. However, he found many of the photographic prints difficult to interpret, because the lesions were not clearly seen. This is a fault of the reproduction, and the reviewer is worried lest many non-radiological readers might be discouraged by a failure to achieve a worth-while diagnostic score. Even on reading the well written descriptive answers, the lesions in many were still not visible. This is unfortunate because the radiographs are well chosen and cover a wide area of different pathologies. It is hoped that in future editions this fault will be corrected.

Allowing for this, the reviewer would recommend this book to all those students and young postgraduates who are looking for a clear account of how to interpret the plain radiographs they will see in daily practice. This has been a relatively neglected area in most radiological text books and Dr Bretland has gone some way to correcting it.

\section{Gastroenterology. An Integrated Course}

(2nd Edition). By Iain E. Gillespie and T. J. Thomson. Pp. 294, illustrated, soft cover. Churchill Livingstone: Edinburgh, 1977. £3.95.

This book, which is based on a course given to 4th-year students at Glasgow Medical School, is primarily intended for an undergraduate audience. An integrated approach has been adopted and the whole of medical and surgical gastroenterology, including a chapter on the mouth, and a chapter on gastrointestinal disease in general practice are dealt with in 284 pages. Consequently only basic facts are presented and controversial issues are strictly eschewed. Something of a surgical bias is also detectable, with only 34 pages dealing with liver disease, whereas 22 pages are devoted to the proctodaeum.

Despite its multiple authorship the book is ably and uniformly written and it is well illustrated throughout. Simple line drawings are employed to clarify the text and there are good quality reproductions of X-ray and histological material. The book should appeal particularly to those medical students desirous of a didactic approach. It is of doubtful value, however, for the postgraduate.

\section{Gynaecological Laparoscopy \\ The Report of the Working Party of the Confidential Enquiry into Gynaecological Laparoscopy}

Edited by G. Chamberlain and J. Carron Brown. Pp. 165, illustrated. Royal College of Obstetricians and Gynaecologists: London, 1978. £2.50.

A survey of patients undergoing gynaecological laparoscopy in the United Kingdom was carried out between April 1st 1976 and March 31 st 1977 and the information contained in over 50000 completed questionnaires has been duly analysed and presented in book form. A facsimile of the questionnaire form is included at the end of the report.

It is difficult to see who will benefit from reading this report, nor is it possible to assess whether the results justify the enormous expenditure of effort and time on the part of so many practising doctors. Those who have been using the technique for a number of years are not going to learn anything that they were not aware of already and those in training, both gynaecologists and anaesthetists, will learn more quickly and in greater depth if they work for seniors already versed in the procedure. It is to be hoped that this report does not open up a floodgate for similar ones dealing with other forms of endoscopy. All investigational techniques carry some hazard and it behoves clinicians to weigh up advantages of any technique before employing it. Once adopted, then the risk factors will be taken into account each time it is used and a report such as this is not going to influence the decision.

Man at High Altitude. The Pathophysiology of Acclimatization and Adaptation

By Donald Heath and David Reid Williams. Foreword by Sir Cyril Astley Clarke. Pp. 292, illustrated. Churchill Livingstone: Edinburgh, London, New York. £12.50.

This book incorporates the wide personal experience over the past decade of the authors in the study of Man at High Altitude in the Andes and subsequently extrapolated to the laboratories of the Department of Pathology at the University of Liverpool. The pathophysiology of acclimatization and adaptation to high altitudes is described dealing both with the clinical and pathophysiological aspects of all organ systems which may be effected. This book has particular 
clinical relevance, because many human cardiopulmonary diseases are characterized by chronic hypoxia. Furthermore, with the ever increasing availability of air travel, clinicians have to be aware of the problems of high altitude and their patients' disease.

This book is particularly pleasing to read because the authors have a very engaging and lively style heightened by their many personal experiences in the Andes and have broadened its authority by an extensive reference section at the end of most chapters. These references are particularly valuable for they deal not only with the historical aspect of the subject, but also include recent references of high altitude investigation.

As outlined by Sir Cyril Clarke in his foreword, Nature has produced a ready-made experiment for mankind in the environment of Man at High Altitude. The effect of high altitude on the physique of man, on the ventilation/perfusion performance of the lungs, of high altitude on blood rheology, the carotid bodies and the pulmonary vasculature is particularly interesting to read. Actual disease entities produced by high altitude such as acute mountain sickness, high altitude pulmonary oedema and Monge's disease form instructive chapters. The effect of high altitude on all organ systems is reviewed with particularly good sections on the cardiovascular system and endocrine systems.

Chapters on the adaptation and acclimatization to high altitude are relevant to modern medical practice with a further interesting section on athletic performance at moderately high altitudes, as exemplified by the Olympic Games in Mexico City.

This book can be highly recommended, not only for the high educational content on the effect of man at high altitude, but also for its pleasing literary style enhanced by the unique personal experiences of the authors. It should be of interest to a wide spectrum of medical readers both at the undergraduate and postgraduate level.

\section{Medical Data Interpretation for MRCP}

By Roger Gabriel and Cynthia M. Gabriel. Pp. 162, illustrated. Butterworths: London, etc., 1978. $£ 2.95$.

This, the latest of many recent publications designed to provide succour for those battling in the MRCP exam, is intended to give practice in the written section of Part II. There are 10 chapters, each one devoted to a speciality such as Cardiology or Renal Disease with, on average, 30 items in each. These consist usually of a short clinical problem followed by a number of questions. The answers, with explanations, are given in the second half of the book.

The relevance to clinical realities of considering highly selected data in isolation such as the cardiac index, or being asked to suggest a diagnosis when give-away data such as heel/pad thickness, are provided, is doubtful. There are also problems raised by discussion of an often limited differential diagnosis or by thumb-nail sketches of management which are in many instances, far too dogmatic. Although these faults may largely reflect the format of the book, there are also a number of errors of fact. The electrocardiographic data are particularly weak. We are told that a massive $R$ wave in $V 1$ is seen in acute pulmonary embolism, that voltage criteria for left ventricular hypertrophy hold with left bundle branch block, and that an ECG showing a sinus arrhythmia is a sinus bradycardia.

There are also a remarkable number of spelling mistakes, many of which are repeated consistently and of which "atopic ACTH production" is perhaps the gem.

This book achieves the authors' aims of providing a stimulating means of studying for the exam but until a second edition has eliminated the errors of fact and of spelling it cannot wholeheartedly be recommended.
1001 Multiple Choice Questions and Answers in Surgery

A. J. Harding Rains. Pp. 221. H. K. Lewis: London, $\bar{Z}$ 1978. £4.00.

Every technique of examination, especially in clinical sub- $c$ jects, can be severely criticized. The marks given for essay questions are notoriously variable from one examiner to the other and indeed it has been known for the same examiner marking the same essay question on different occasions to vary the mark from "distinction" to "fail"! Patients provided for long and short clinical cases vary considerably in their $\frac{\bar{\sigma}}{7}$ their ability to give a reasonable history and the ease or $\mathbb{\Phi}$ difficulty of their physical signs. Some of the "pots" used in $\varrho$ pathology vivas, if shaken, look like those glass toys of the Eiffel Tower in a snow storm. Multiple choice questions, $\vec{\nabla}$ with all their faults, at least provide a strictly comparable? situation to every candidate, are marked impartially by the $\overrightarrow{\vec{H}}$ computer and enable a wide range of the factual knowledge $\vec{\omega}$ of the subject to be tested in a limited time. Most of the faults of the MCQs are due, not to the system itself, but to slackness of the examiners in setting the questions.

Whether we like it or not, multiple choice questions are here if to stay, at least until something better comes along. It thus be- or hoves our students to become thoroughly familiar with this $\mathcal{W}^{\circ}$ system and to practise the technique of this type of examination just as they have to practise answering essay questions ${ }^{\circ}$ and viva voce examinations. Fortunately, a number of $\omega^{\omega}$ excellent books are now available on MCQs for medical ?

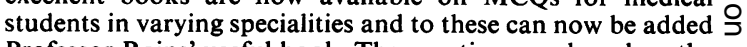
Professor Rains' useful book. The questions are based on the text of what is undoubtedly the most popular surgical textbook in the world, Bailey and Love's "Short Practice of Surgery" which Professor Rains edits in collaboration with Professor David Ritchie. There is a useful introduction on the various types of MCQs and on how to answer them. The questions themselves are divided into 5 groups. The fire $\vec{v}$ 2 parts are questions based serially on the chapter arrange ments in "Short Practice", the first group being sing response and the second providing a choice of answers (determinate type questions). Parts 3 and 4 are similar questions but now set at random with no relationship to the $\bar{\partial}$ chapter form of the textbook and thus more akin to the type of questions students will encounter in an examination.

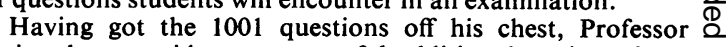
Rains then provides a most useful additional section of $101 \overrightarrow{\vec{F}}$ questions in surgical history which should certainly help $\frac{0}{3}$ to kindle an interest in this fascinating subject and whose answers can be found from the interesting historical footnotes in the text book itself.

This is a book which will certainly appeal to clinical students and Fellowship candidates. Established surgeons might well be tempted to see if they can gain $100 \%$ marks; they are likely, however, to be bowled out by some of Professor Rains' googlies.

Mycotoxic Fungi, Mycotoxins, Mycotoxicoses. An Encyclopedic Handbook

Volume 2: Mycotoxicoses of Domestic and Laboratory Animals, Poultry, and Aquatic Invertebrates and Vertebrates. Edited by T. D. WYLIE and L. G. MOREHOUSE. N Pp. 570, illustrated. Marcel Dekker: New York and Basle, 1978. SFrs: 230 (set of 3 Vols. \$156.00).

This second volume of a 3-part handbook on mycotoxins and associated diseases deals with mycotoxicoses of domesticated and laboratory animals. The format chosen deals with the effects of individual mycotoxins on different species of animal, rather than on organ systems. This has led to some duplication of data, but since the handbook is expressly intended to be encyclopaedic, the approach is both logical and advantageous. 